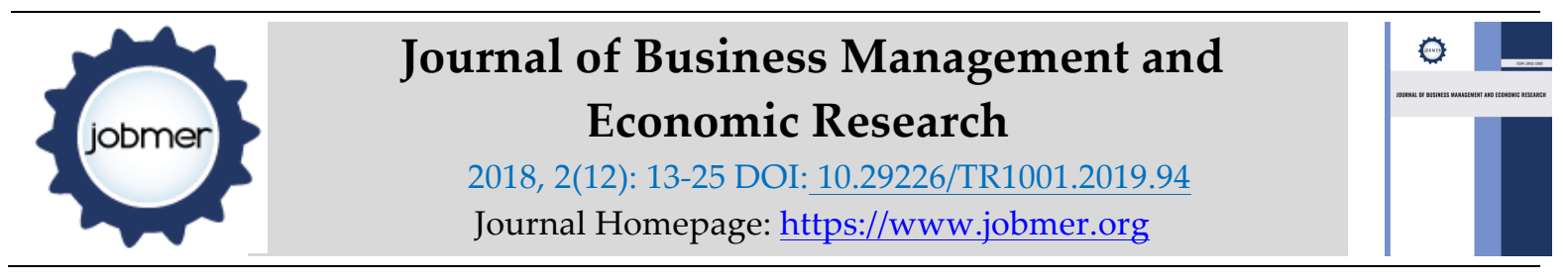

\title{
The Potentialities of RFID-Based Traceability System in the Olives Post-Harvest Stage
}

\author{
Abderahman Rejeb \\ Széchenyi István University, Department of Logistics and Forwarding \\ Egyetem tér 1, 9026 Győr, Hungary, abderrahmen.rejeb@gmail.com
}

\begin{abstract}
Given that the major challenges for olive production and for producers are to improve fruit and oil quality, a plethora of analytical techniques are carried out for the purpose of traceability and validation of the authenticity of olive oil. However, due to many considerations, all of these methods remain only applied in the testing phase. Therefore, the olive oil supply chain actors have to cope with the new advancements in intelligent food logistics to address some traceability concerns. In this specific line of research, this paper aims to propose a theoretical framework for embedding RFID into the traceability system of olives in the post-harvest stage. Then, a discussion is centered on the potentialities of adopting RFID in this target process. RFID is a new emerging technology which opens up windows of opportunities for an effective and efficient traceability system design in the supply chain and logistics of a valuable commodity.
\end{abstract}

Keywords: Olive Oil Supply Chain, Analytical Techniques, RFID, Traceability.

\section{Introduction}

Virgin olive oil is a precious commodity with excellent nutritional characteristics. Besides to its health and sensory properties, it constitutes a typical source of food and income throughout the Mediterranean region (Papaefthimiou, Ventouris, \& Tabakis, n.d.) (Mansour, Gargouri, Flamini, \& Bouaziz, 2015). It is the result of a mechanical extraction from fruits and it can be directly consumed by the addition of chemical substances (Manel Issaoui et al., 2015). The International Olive Council has classified the virgin olive oil under the following categories: extra virgin olive oil (the top quality), virgin olive oil, ordinary virgin olive oil and lampante virgin olive oil (unfit for consumption) (International Olive Council, 2015). This classification is hinged on the quality features such as the pressing from which olive oil comes, the flavor and the acidity. In fact, the quality of virgin olive oil is associated with many endogenous and exogenous factors. The geographic origin of the olives (Manel Issaoui et al., 2010) (Ouni et al., 2011), the extraction systems and cultivars (Issaoui et al., 2009) and the agricultural practices impact significantly the quantity and the activity of endogenous enzymes that mainly influence the phenolic profiles and the sensory characteristics of olive oil (Baccouri et al., 2008). Likewise, the method of olive oil extraction, the conditions of storage for olives and virgin olive oil, the packaging materials and shipment conditions constitute the external factors that may exhibit a significant impact on quality as demonstrated in may previous studies (Vekiari, Papadopouloua, \& Koutsaftakisb, 2002) (Pristouri, Badeka, \& Kontominas, 2010)(Valli et al., 2013) (Lozano-Sánchez et al., 
2012)(M Issaoui et al., 2009). Therefore, several parameters must be properly applied to derive a high quality of virgin olive oil that will go from farm to fork.

Due to its high price compared to other vegetable oils, virgin olive oil is highly subject to the risk of adulteration, mislabeling and misleading. The fraudulent practices include inter alia, the adulterations in the composition of the organoleptic character of the product and of geographical indications, adulteration (addition or subtraction of specific components of the product), sophistication (addition of foreign substances), and falsification (substitutions of specific components) (Girelli, Del Coco, \& Fanizzi, 2017). These misconducts are motivated by the search for more economic benefits from the sale of unauthentic virgin olive oil. To respond to the concerns of public and quality control evaluators of olive oil, it is necessary to study the traceability of virgin olive oil. With regard to this approach, The EU commission makes a narrow definition of traceability in the context of food industry as the ability to trace and follow a food, feed, food-producing animal or substance intended to be, or expected to be incorporated into a food or feed, through all stages of production, processing and distribution. Simply stated, it is an effective method which aims to ensure food safety and quality and to reduce the costs associated with recalls (Regattieri, Gamberi, \& Manzini, 2007). Drawing on this perspective, producers' awareness of the potentialities of adopting adequate traceability systems has been raised to improve transparency in their production. Besides, a traceability system as defined by Giametta \& Sciarrone (2009) is intended to identify all the farms/businesses involved in the manufacturing of the product in question (including their organizations and flows of materials) as well as the relevant products or components whose tracing and backtracking is necessary to put in place the traceability system in question. As a result, the tighter control of producing and importing countries of virgin olive oil, the effective marketability of olive oil products and the plethora of analytical techniques and methods for ensuring the authenticity of olive oil are pushed to a new stage by government regulations and consumers' requirements.

Considering the potentialities of technology in the supply chain, its adoption in the agricultural supply chain is very important. For most olive oil businesses in which denominations of origin is mandatory, the use of a traceability system could be highly leveraged with the adoption of the emerging technology of radio frequency identification (RFID). RFID is a generic term for technologies that use radio waves to automatically identify objects (Roberts, 2006). This implies to say that it associates an RFID tag unique identifier with the concerned object. The increasing popularity of RFID is manifested by the favorable results it brings to the agricultural supply chain. In view of this fact, several companies and even some European projects proposed the use of RFID technology to build full traceability systems (Expósito \& Cuiñas, 2013).

This study aims to propose a theoretical framework of an RFID-based traceability system for olives. Even though many scholars have studied the applications of RFID in the agriculture sector, very few studies dealt with the adoption of RFID in olive oil supply chain and to the best of my knowledge, this is the first paper to propose RFID-based traceability system for olives and to discuss its potentialities at the post-harvest stage. Hence, the remainder of the paper begins with screening the literature of the RFID-based traceability systems in the agriculture, the different analytical methods for ensuring the authenticity of virgin oil. The following part will present the theoretical framework of the RFID-based traceability system of olives in the post-harvest stage accompanied with a discussion of its functioning and its contributions to the industry and to businesses involved in the olive oil value chain. The last part will cover a brief conclusion for the paper.

\section{Literature Review}

As supported by a vast amount of facts, the applications of RFID in the agro-food have attracted the attention of academicians and researchers in the last years (Ruiz-Garcia \& Lunadei, 2011). Many scholars have studied the applications of RFID and their implementation in the agro-food supply chains. To cite some of them, Qian et al. (2012) proposed an RFID-based traceability system for a 
wheat flour mill in China by incorporating the RFID technology and 2D barcodes. They studied the cost-benefit of the system and found that the total cost of the system increased by $17.2 \%$ but generating an increase in sales income by $32.5 \%$ which therefore validates the potentialities of the suggested traceability system in medium and large wheat mill enterprises in China. Chunxia, Weimin, Yingyan, \& Huiyuan (2009) discussed the RFID adoption in the vegetable supply chain which contains the vegetable cultivation, processing, storage, transporting and retailing in China. They explored the role of this technology in improving the efficiency of the vegetable supply chain and the existing challenges and obstacles to its adoption (e.g. technology, standard, and cost challenges). In the same vein, Yang \& Wang (2012) introduced the basic working principle and technical characteristics to establish an RFID-based traceability system for vegetable quality safety in China. Also, Hertog et al. (2008) proposed the implementation of a quality change model based on smart traceability system for tomatoes in Belgium. Tomatoes were stored at an artificial temperature scenario to validate the quality changes model and RFID labels with integrated temperature sensors were used to monitor the whole supply chain of tomatoes from the grower to the retailer. Their experimental findings indicate that the integration of quality change models with RFID-based traceability systems is beneficial for the satisfaction of consumers. In the manufacturing and processing of wines, Wang, Kowk, \& Ip (2012) suggested an RFID-based quality evaluation system that combines RFID and sensor technologies in order to monitor the whole supply chain of wine. Their system can discover accidents in time to reduce losses and prevent therefore counterfeit. Moreover, Exposito, Gay-Fernandez, \& Cuinas (2013) studied the traceability in wine sector and proposed a system that traces the wine from vineyard to the consumer glass based on the joint use of RFID technology and Wireless Sensor Networks (WSN). They came to conclude that the system could provide a competitive advantage to the companies operating in the wine production sector by improving the visibility of the processes performed and the associated control over the quality of wines. In the dairy cheese production, Barge, Gay, Merlino, \& Tortia (2014) designed a complete itemlevel RFID traceability system for a high-value, pressed, long-ripened cheese. They experimented with the different techniques for fixing the tags to the cheese to automatically record the cheese wheels movements during the production, handling in the maturing room and warehouse, delivery, packing and selling stages. The authors conclude that the successful integration of an RFID system in a food production process depends on multiple factors related to the RFID devices features and the production process layout. Similarly, Regattieri et al. (2007) developed a general framework for the traceability of cheese products based on an integration of alphanumerical codes and RFID technology. Their study allows to conclude that the proposed system is working well with very good outcomes for both cheese producers and consumers.

RFID technology has been widely discussed in the plant monitoring. For the purpose of tree identification, RFID tags can be embedded in the tree trunks without a significant impact on plant health, growth and production. Several tests have been conducted in different kinds of plants such as citrus, grapevine plants and Prunus spp (Bowman, 2010) (Luvisi et al., 2010) (Luvisi et al., 2011). All the marked plants can be easily monitored and will be able to supply various information including identity, growth parameters, susceptibility to biotic stress factors, and productivity. All the related information is accessible via an online database (Luvisi et al., 2010). Not only that, RFID tags can be also attached to the products (e.g., seeds, fertilizers, etc.) and the readers installed in the machinery, detecting what is put into the implement's hopper or tank (Ruiz-Garcia \& Lunadei, 2011). This results in more transparency and quality assurance by having a grasp of all the details related to fertilizers spread patterns, pesticides, and insecticides used in the process (Watts, Miller, \& Godwin, 2002) (Peets, Gasparin, Blackburn, \& Godwin, 2009). In the same line, Ampatzidis et al. (2009) proposed the use of RFID to match bins of harvested fruits with corresponding trees during harvesting in orchards. Their system proved to be successful in overcoming the limitations of existing yield mapping systems for manual fresh fruit harvesting and in the case of the unavailability of GPS data caused by foliage. 
Since olive oils are subject to the combination of high and low-grade virgin oil and the inclusion of numerous edible oils, several analytical techniques are deployed to detect adulteration and ensure the authenticity of virgin olive oil (Ben-Ayed, Kamoun-Grati, \& Rebai, 2013). Several scholars review the technological advancement in the traceability of olive oil using several techniques such as the isotope analysis (Camin et al., 2010), chemometrics (Bevilacqua, Bucci, Magrí, Magrí, \& Marini, 2012), and DNA analysis (Pasqualone, Montemurro, Caponio, \& Blanco, 2004). The isotope analysis has emerged as a powerful tool for tracing the geographical origin of the agro-food products and varying degrees of success have been recorded in identifying and differentiating the different agro-food products including olive oil (Badia-Melis, Mishra, \& Ruiz-García, 2015). Bevilacqua et al. (2012) analyzed the potential of infrared spectroscopic fingerprinting coupled with chemometric discriminant and modeling classification techniques in the traceability of olive oil samples with the protected designation. Their obtained results confirmed the high accuracy and the affordability of the infrared spectroscopy with chemometrics besides to the non-invasive/non-destructive techniques of olive oil traceability. In addition, Ben-Ayed et al. (2013) reviewed the DNA-based technology to characterize olive oil and detect possible adulteration. They stated that the genetic identity is the most appropriate method for overcoming the shortfalls of most chemical analyses with limited significance. According to Ben-Ayed et al. (2013), the blend of olive oils of the same category but from different provenances makes the use of DNA markers suitable in providing unequivocal identification for authentication and traceability.

Despite the importance of these techniques in authenticating olive oil and discriminating it from different geographical origins, these analytical instruments are limitedly available and costly to purchase (Othman, Salim, Moosa, \& Mostapha, 2006). Plus, there is a lack of technical capability and expertise among the national food laboratories to implement these techniques such as the difficulty of databases collections, proficiency testing, statistical data for chemical profiling. The olive oil monitoring has been conducted with the use of offline sample analysis wherein the sampling needs costly instruments (e.g., accurate electrical balances, microscopes, and automatic particle counters) and high time demanding human processes which thus preclude the early diagnosis of olive oil and yield to system failures and prevention (Papaefthimiou et al., n.d.). Also, the verification of the geographical origin for cultivar should be done by a comparison with known, authentic and reliable samples. Therefore, these new advancements can only help to overcome some gaps such as the historical control but they are still applied only in the testing phases and they require a big deployment of resources not affordable always for the olive oil supply chain partners. Owing to this, the present study aims to engage the technology of RFID in addition to these advancements in the olive oil traceability at the harvest stage. This research topic remains unaddressed in the existing and increasing literature of intelligent food logistics. Hence, it comes the idea to advance olive oil traceability in this direction. 


\section{The Typical Design of Olive Oil Value Chain and the Theoretical Framework of the RFID-based Traceability System}

\subsection{The Olive Oil Value Chain}

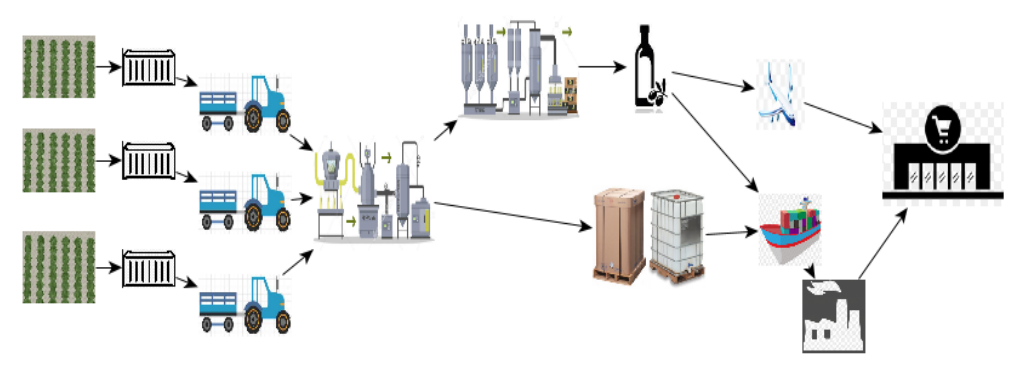

Figure 1. The Typical design of the olive oil value chain

As shown in figure 1, the value chain begins in olive orchards where farmers carried out the different cultivation activities. These include the installation of irrigation by droplet, the planting and the better selection of olive groves variety, the sanitary treatments applied at the trees (e.g., insecticides, pruning, etc.), and the scheduling of harvesting and olives collection. Thus, a suitable environment and proper cultural care are necessary for the full development of the agronomic characteristics of the trees (Boskou, 2000). In addition to the cultural care, other measures are taken to ensure a more steady fruit production and to mitigate the fluctuations by encouraging the use of irrigation (intensive or hyper-intensive growing) and increasing the proportion of irrigated olive orchards (Angulo et al., 2011).

The harvesting stage (involving pruning) constitutes the most critical and expensive operation which affects significantly the production cost and the quality of produced olive oil (Abenavoli \& Marcianò, 2013). The methods employed to harvest depend on cultural techniques, orographic conditions of the ground, and variety of olive trees. In the usual way, the tarps are drawn under the foliage of the olive tree and the workers gently dislodge the olives using their hands or a rake. The wooden poles are usually used to beat the far unreachable fruiting boughs. The workers collect the olives fallen into the nets and gather up any strays on the ground in the traditional jute sacks (or plastic ones) after clearing them from leaves and twigs and then they transport the olives immediately to the oil mill. Olives are harvested at the point of ripening; meaning that they reach the maturity state or the green-yellow or black-purple stage (Boskou, 2000) and the oil accumulation in the olives is interrupted (García \& Yousfi, 2006).

In order to avoid the undesirable enzymatic reaction and the oxidative and fermentative processes (e.g., yeasts and molds...), a fast and proper to-the-last mile transport is necessary to carry olives to the olive mill. After that, the olives will be stored temporarily and spread in shallow layers and kept in cool and dry areas. It is highly recommended that the time lag between harvesting and processing should be as minimum as possible to retain the quality characteristics of olives. Subsequent to that, the olive extraction phase comprises mainly 4 operations as illustrated in figure 2 . 


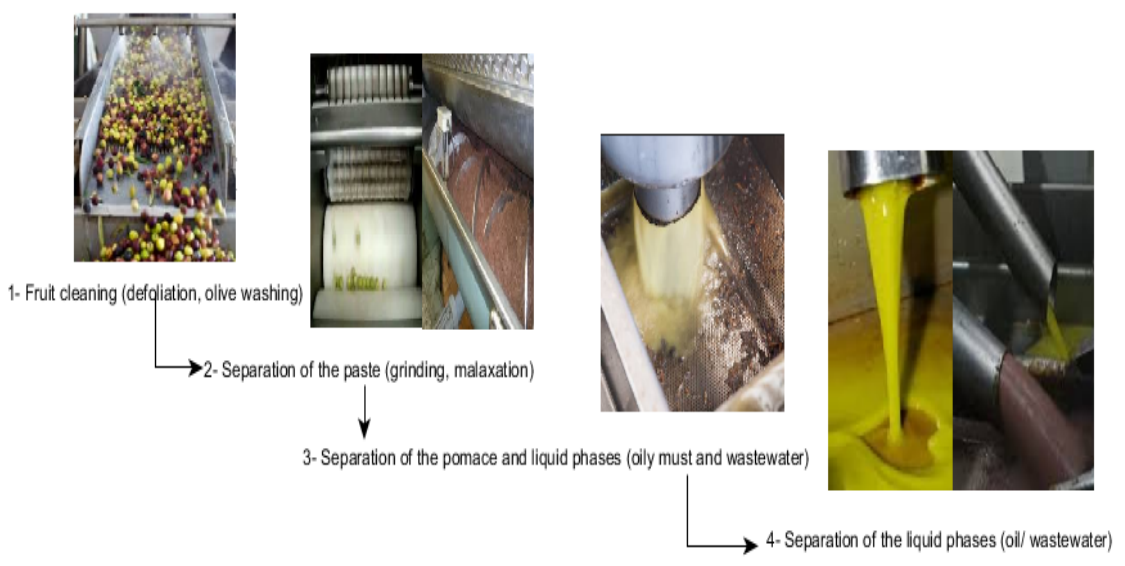

Figure 2. The olive oil extraction process (adapted from (Boskou, 2000))

The process starts by washing, cleaning and deleafing olive fruits. Defoliators are used to delete perfectly leaves, twigs and other impurities from all the picked olives through a powerful airflow generated from a calibrated air jet. To improve the washer efficiency, the washing vat is equipped with a shaker that shakes any impurities through screens as well as an air injection system to create turbulence in the mass (Boskou, 2000). The olives are then crushed with a hammer crusher (or stone mills) to turn them into a fine paste. This paste is then malaxed in order to make it uniform and to agglomerate the oil droplets. The separation of the solid and liquid phase (i.e., the pomace, the oily must and the wastewater) goes through the pressing step. The obtained olive paste is spread into mats or fiber disks which are stacked onto a press plate, where a hydraulic piston carries out the pressure. As a result of this, the pomace and the liquid phase are produced. The final liquid phase containing oil and vegetation water is separated by a standard process of decantation (Manel Issaoui et al., 2015).

\subsection{Theoretical Framework of RFID- Based Traceability System}

RFID is an emerging internet of things technology which is increasingly embedded in logistics and supply chain management. It relies on the wireless radio waves to identify objects from a distance without the necessity of line of sight or physical contact. The technology consists mainly of 3 parts: tags (or transponder, labels), antenna and readers (also called interrogators or coupling devices). For the purpose of tracking olives, RFID technology can be applied to ensure a sound traceability of the harvested olives as shown in figure 3. 


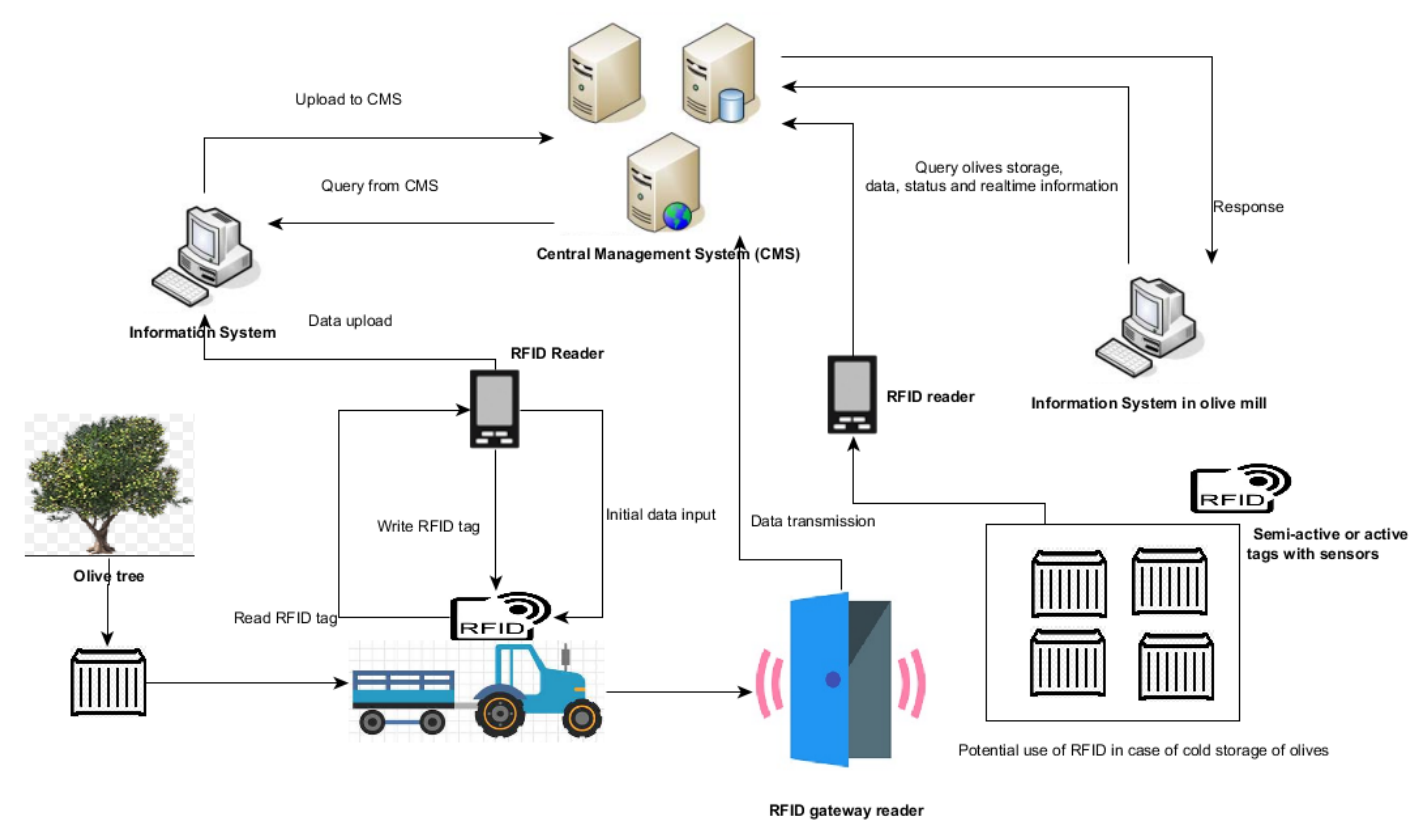

Figure 3. Conceptual flowchart of the RFID-based traceability system in the post-harvest stage

The proposed system covers only all the activities prior to the olive oil extraction (i.e., the postharvest and the storage of olives). It addresses the questions related to the variety of olives, the orchard from which they are harvested, the quantity, and the storage handlings. The system will help to monitor the olives from the harvesting to the storage stage in the olive mill by gathering all the information in the central management system.

After collecting olives, it is highly recommended to separate the olives harvested from the trees and those collected from the soil. The perforated boxes from the sides and the base will be chosen due to their roles to ventilate olives and delay the fermentation processes during the storage phase (García \& Yousfi, 2006). Besides, they imply also the introduction of palletization system at further stages which can minimize the fruits damage caused by handling, save the space and ease RFID attachment to either case or pallet level.

All the information related to the boxes loaded on the tractor or the van track will be entered in a rewritable passive tag attached to the container sides or door. These information trace back the complete history of each box of olives (e.g., the olive variety, the collection date, the olive growers, irrigation practices, the geographic location of the region, orographic conditions, soil slope, and level of mechanization in harvesting, etc.). This helps to avoid the inclusion of non-traced olives and a better monitoring of lots. In addition, the source of olive oil will be clearly defined by knowing the olive variety from which oil is truly derived and thus this could be used latterly in the geographical indications of agricultural products' origin which allows the producers to obtain market recognition and often a premium price (Othman et al., 2006).

These initial data will be encoded in the RFID tag using a reader connected with a computer which the information stored in the tag will be transmitted to and uploaded to the central management system. Through this system, the management function of data collection, processing, remote transmission, and storage will be digitalized. As a consequence, the problems and the failure (either inadvertently or deliberately) inherited by the present paper-based system that passes the information along with the commodity (Othman et al., 2006) will be significantly minimized since RFID uses encryption and includes a trusted security mechanism for data protection. Next, the crates of olives will be transported to the olive mill. The tag attached to the vehicle will be read at the entrance of the mill with a portal reader. The information on the tag will be transferred and stored in the back-end database of the central management system. This reading method enables operational 
efficiency and helps to avoid the collision problem since there is only one reader mounted on the olive mill bay door.

In their study, Abenavoli et al. (2016) suggested the use of QR codes (i.e., two-dimensional codes) printable for the olives containers (e.g., bins, crates, etc.) for the traceability of olives during the harvesting phase. However, they overlooked the problematic readability of barcodes due to their poor resistance to dirt, moisture, and bending; resulting in reduced accuracy of reading rates, particularly in successive handling situation and in difficult environment (Ollivier, 1995) (Moore, 1999). Besides, depending on environmental conditions and maintenance, barcode read rates often decline to less than $90 \%$ over time, unlike RFID which can achieve $99.5 \%$ to $100 \%$ first-pass read rates (Instruments, 2006). Also, the major advantages of RFID over barcodes are that it does not require line of sight reading, most RFID tags are highly resistant to environmental temperature and other external factors, and can be read and re-programmed at least 300,000 times before replacement (DeJong, 1998). This leads to say that in our proposed system, the tags attached to the vehicles containers transporting the olive fruits from the farms to the olive mill can be used many times. Although barcode-based systems are claimed to provide most of the needed functionality, RFID is still a very promising technology to unprecedented levels and will remain as such thanks to its potentialities with reference to olives traceability.

The storage is the most critical stage in defining the quality of olive oil. The poor handling of olives during the time between harvesting and processing results in great deterioration of olive oil (García \& Yousfi, 2006). To avoid the degenerative processes caused by the improper handling and heaping of fruit piles, the industry is recommended to reduce the interval time between harvesting and processing by an increase in the milling capacity. Nevertheless, the investment in the equipment necessary for preventing the accumulation of olive fruits might be not profitable and feasible since it will only be used in the peak season (i.e., January). Therefore, the implementation of an RFID system could help the members who deal with stages of olive storage and processing to monitor the capacity of the mill in a way to set quickly a JOB or action to match the processing needs of the mill with the appropriate quantity of olives to be harvested. As a result, this implies to say that the RFID-enabled system will yield to a pull-based approach in which problems linked to the prolonged time of olive fruits storage and the presence of microorganisms will be minimized to a large extent, thus leading afterward to the preservation of olive oil quality and the maintenance of its oxidative stability (El et al., 2018).

In case of resorting to the use of refrigeration for the storage of olives intended for oil to delay the deterioration activity of pathogens and in which the following requirements should be met: a cool room capable of storing the olive fruits that cannot be absorbed by the mill machinery, a temperature of $5^{\circ} \mathrm{C}$ over a period time $\leq 12$ hours (García \& Yousfi, 2006), the technological compatibility of RFID corresponds to an important degree with the cold storage of olives. In fact, some RFID tags with embedded temperature sensors can be used to automatically capture all the related data that are critical to the quality and the safety of olive fruits (such as the history of temperature, humidity, and time period), thus providing the central management system with a real-time description of the state of the storage. Moreover, the sensors can be set to work as an alarm, being able to work only within a certain temperature range (Costa et al., 2013) and alert the responsible person if there is an excess over threshold limits. Practically, this can be done by installing commercial active and semi-passive tags (Amador, Emond, \& Nunes, 2009) (Jedermann, Ruiz-Garcia, \& Lang, 2009) in the walls, the pallets or the boxes of olives which are capable of monitoring efficiently and consistently the temperature.

With regard to the cost of RFID technology adoption, tagging applied to the transport-unit level (i.e., vehicle, tractors or vans), pallets or storage containers can generate many potential benefits in terms of considerable reduction in capital investment (Kärkkäinen, 2003). This is because RFID tags are not embedded within the individual consumer packages, where sometimes it is too costly and expensive to afford them, but they are recurrently utilized in the traceability of harvested olives. In this way, the 
RFID-based traceability system is concerned with the tracking of the content and not the package of olive oil products, hence furnishes a link back to the point of origin of olive oil (i.e., olive orchards).

As a result, the investment in transponders might achieve a great cost efficiency in the long run since RFID tags will be continuously utilized (Kärkkäinen, 2003). Consistently with (Shutzberg, 2004) who points out that the application of RFID in specific processes in the chain can save a company from important costs, the automation of traceability brought by RFID will have an important impact on reducing the time spent in collecting, recording, and retrieving of data related to the harvested olives. Besides, it helps the handlers to assess the precise permanence of the olives at the harvesting and preprocessing stage. Plus, Savings in cost may be attainable through automating the checkout process and reducing the human intervention associated with storage management. For that reason, companies operating in the olive oil industry may consider the implementation of RFID technology in the post-harvest stage because a more simplified and focused approach to RFID incurs much less risk in implementation (Fontanella \& Bilodeau, 2003) and the investment payback may come in quiet short-term since the investment is targeted to a specific process.

A potential synergy between olive oil supply chain actors may be achieved through the integration between the central management system and the partners' information systems based on the use of web-service technology (Meixell, 2006). All the partners of the chain can access information in the central management system using the internet. The share of information between the participants helps in turn to improve the visibility of the chain by providing exhaustive information on the origin of the product in question and raises consumers' confidence in the originality of the supplied olive oil.

Aside from the efforts made by many countries to improve the competitiveness of the olive oil in both the domestic and international market and to promote the marketability of the olive oil products through the Protected Designation of Origin (PDO), Protected Geographical Indication (PGI) and Traditional Specialty Guaranteed (TSG) in varietals indication (Abdelhamid et al., 2013), the governments may support and stimulate the olive oil industry by encouraging the deployment of RFID and information technologies due to their potential benefits to not only the producers of olive oil but also to the technical staff in charge of the quality certification (i.e., the Regulatory Board of PDO) by speeding up the information access, saving the time and simplifying the tasks far different than for the existing paper-based system of data record and collection. Although this technology entails some changes in the enterprise's business processes, the implementation of RFID along with the appropriate information structure can enable a sound traceability to be spread over a very important stage in the olive oil supply chain at small, lowering cost of RFID (Ruiz-Garcia \& Lunadei, 2011). The availability of a cheap labor force in some producing countries could justify to a certain extent the use of RFID which remains in all cases a one step forward to voluntary traceability raised from the conviction of a better organized and improved work along the production chain (Expósito \& Cuiñas, 2013).

\section{Conclusion and Recommendations}

Considering the benefits that new emerging technologies can bring to the supply chain, this paper aims to investigate the potentialities of RFID adoption in the olives post-harvest stage. Besides to the analytical techniques used to detect the authenticity of olive oil, RFID technology could leverage the internal traceability and helps to smooth the internal procedures of the olive oil producers to trace the origin of olive fruits after their harvest. The use of RFID implies a traceability with a high-level resolution and near-perfect information visibility throughout the supply chain. Furthermore, the information related to the olives variety, the orchards from where they are collected, the orographic conditions of the groves, and the storage status of fruits in the olive mill, etc. could be speedily traced through the proposed RFID system with cost savings and minimum human intervention. RFID could potentially be used in the refrigeration of olives to monitor consistently the temperature in the cold 
storage rooms and thus alerts the responsible operator to take the necessary measures in case of threshold violation.

For more competitiveness, producing countries could capitalize on the advantages brought by the use of RFID-enabled traceability in the post-harvest stage of olives and set into motion the beginnings of RFID technology adoption in an industry highly concerned by traceability but which uses it little (Karâa \& Moranab, 2016). This can be achieved through a set of material and immaterial incentives (funds, promotion and advertising of RFID-enabled traceability systems, grants, etc.) since the implementation costs of RFID could be a restricting factor for some olive oil producers and exporters. Also, raising the producers' awareness about the promising opportunities of RFID and its ability to improve the transparency of their production processes may bring impactful benefits that span across all the olive oil supply chain members.

Despite all these benefits offered by the RFID technology, several issues may raise concerns associated with the quality of information input within the traceability system and the degree of its reliability. Besides, the evaluation of the cost-benefit analysis, the technical and economic feasibility of an RFIDbased traceability system in the post-harvest stage of olives, and the deployment of RFID in other processes may be addressed in future research.

\section{Acknowledgement}

This work was supported under the project reference: EFOP- 3.6.1-16-2016-00017 Internationalisation, creation of teaching, research and student supplies, development of knowledge and technology transfer as the means of intelligent specialization at Széchenyi István University.

\section{References}

Abdelhamid, S., Gouta, H., Gharsallaoui, M., Ghrab, M., Kwon, T., Yoon, I., \& Byun, M. O. (2013). A Review on Current Status of Olive and Olive Oil Production in Tunisia, 25(4), 351-357.

Abenavoli, L. M., Cuzzupoli, F., Chiaravalloti, V., \& Proto, A. R. (2016). Traceability system of olive oil: A case study based on the performance of a new software cloud. Agronomy Research, 14(4), 1247-1256.

Abenavoli, L. M., \& Marcianò, C. (2013). Technical and economic analysis of alternative pruning systems in high dimensions olive trees in Calabria. Agronomy Research, 11(1).

Amador, C., Emond, J. P., \& Nunes, M. C. do N. (2009). Application of RFID technologies in the temperature mapping of the pineapple supply chain. Sensing and Instrumentation for Food Quality and Safety, 3(1), 26-33. https://doi.org/10.1007/s11694-009-9072-6

Ampatzidis, Y. G., Vougioukas, S. G., Bochtis, D. D., \& Tsatsarelis, C. A. (2009). A yield mapping system for hand-harvested fruits based on RFID and GPS location technologies: Field testing. Precision Agriculture, 10(1), 63-72. https://doi.org/10.1007/s11119-008-9095-8

Angulo, A. M., Mtimet, N., Dhehibi, B., Atwi, M., Youssef, O. Ben, Gil, J. M., \& Sai, M. B. (2011). A revisited gravity equation in trade flow analysis: an application to the case of Tunisian olive oil exports. Investigaciones Regionales, 21(december), 225-239. Retrieved from http://dialnet.unirioja.es/descarga/articulo/4226669.pdf\%5Cnhttp://dialnet.unirioja.es/servlet/arti culo? codigo $=4226669$

Baccouri, O., Bendini, A., Cerretani, L., Guerfel, M., Baccouri, B., Lercker, G., ... Daoud Ben Miled, D. (2008). Comparative study on volatile compounds from Tunisian and Sicilian monovarietal virgin olive oils. Food Chemistry, 111(2), 322-328. https://doi.org/10.1016/j.foodchem.2008.03.066

Badia-Melis, R., Mishra, P., \& Ruiz-García, L. (2015). Food traceability: New trends and recent advances. A review. Food Control, 57, 393-401. https://doi.org/10.1016/j.foodcont.2015.05.005

Barge, P., Gay, P., Merlino, V., \& Tortia, C. (2014). Item-level Radio-Frequency IDentification for the 
traceability of food products: Application on a dairy product. Journal of Food Engineering, 125(1), 119-130. https://doi.org/10.1016/j.jfoodeng.2013.10.019

Ben-Ayed, R., Kamoun-Grati, N., \& Rebai, A. (2013). An overview of the authentication of olive tree and oil. Comprehensive Reviews in Food Science and Food Safety, 12(2), 218-227. https://doi.org/10.1111/1541-4337.12003

Bevilacqua, M., Bucci, R., Magrí, A. D., Magrí, A. L., \& Marini, F. (2012). Tracing the origin of extra virgin olive oils by infrared spectroscopy and chemometrics: A case study. Analytica Chimica Acta, 717. https://doi.org/10.1016/j.aca.2011.12.035

Boskou, D. (2000). Olive oil (Vol. 87). https://doi.org/10.1079/9781845934583.0279

Bowman, K. D. (2010). Longevity of radiofrequency identification device microchips in citrus trees. HortScience, 45(3), 451-452.

Camin, F., Larcher, R., Nicolini, G., Bontempo, L., Bertoldi, D., Perini, M., ... Hoogewerff, J. (2010). Isotopic and elemental data for tracing the origin of European olive oils. Journal of Agricultural and Food Chemistry, 58(1), 570-577. https://doi.org/10.1021/jf902814s

Chunxia, W., Weimin, Y., Yingyan, P., \& Huiyuan, X. (2009). Research on RFID technology adoption of vegetable supply chain in China. In Proceedings - 2009 International Forum on Information Technology and Applications, IFITA 2009 (Vol. 2, pp. 669-672). https://doi.org/10.1109/IFITA.2009.200

Costa, C., Antonucci, F., Pallottino, F., Aguzzi, J., Sarriá, D., \& Menesatti, P. (2013). A Review on Agrifood Supply Chain Traceability by Means of RFID Technology. Food and Bioprocess Technology, 6(2), 353-366. https://doi.org/10.1007/s11947-012-0958-7

DeJong, C. . (1998). Material handling tunes in. Automotive Manufacturing \& Production, 110(7), 66-9. Retrieved from https://elibrary.ru/item.asp?id=3352225

Du, J., Li, P., Gao, W., Wang, D., Wang, Q., \& Zhu, Y. (2010). An application of rfid in monitoring agricultural material products. IFIP Advances in Information and Communication Technology, 317, 254-259. https://doi.org/10.1007/978-3-642-12220-0_37

El, N., Samaniego-sánchez, C., Asehraou, A., Jesús, R., Villalón-mir, M., \& Serrana, H. L. De. (2018). Effects of olive storage and packaging on microbial and fatty acids profiles of olive oil produced in traditional mills in Morocco, 2508(3), 854-863.

Expósito, I., \& Cuiñas, I. (2013). Exploring the limitations on RFID technology in traceability systems at beverage factories. International Journal of Antennas and Propagation, 2013. https://doi.org/10.1155/2013/916526

Exposito, I., Gay-Fernandez, J. A., \& Cuinas, I. (2013). A Complete Traceability System for a Wine Supply Chain Using Radio-Frequency Identification and Wireless Sensor Networks. Ieee Antennas and Propagation Magazine, 55(2), 255-267. https://doi.org/10.1109/MAP.2013.6529365

Fontanella, J., \& Bilodeau, M. (2003). Finding the ROI in RFID. AMR Research Alert, (Oktober).

García, J. M., \& Yousfi, K. (2006). The postharvest of mill olives. Grasas Y Aceites, 57(1), 16-24. https://doi.org/10.3989/gya.2006.v57.i1.18

Giametta, F., \& Sciarrone, G. (2009). An integrated technological traceability model in the olive growing production chain, (528), 19-26.

Girelli, C. R., Del Coco, L., \& Fanizzi, F. P. (2017). Tunisian extra virgin olive oil traceability in the EEC market: Tunisian/Italian (Coratina) EVOOs blend as a case study. Sustainability (Switzerland), 9(8). https://doi.org/10.3390/su9081471

Hertog, M. L. A. T. M., Yudhakusuma, R. F., Snoekx, P., De Baerdemaeker, J., \& Nicolaï, B. M. (2008). Smart traceability systems to satisfy consumer expectations. In Acta Horticulturae (Vol. 768, pp. 407-415). https://doi.org/10.17660/ActaHortic.2008.768.53

Instruments, T. (2006). Wedge Transponder RI-TRP-R9BK RITRP-W9WK. Retrieved from 
http://www.ti.com/lit/ug/scbu037/scbu037.pdf (last access 04 August 2018)

International Olive Council. (2015). Trade Standard Applying To Olive Oils and Olive-Pomace Oils. Retrieved from http://www.internationaloliveoil.org/

Issaoui, M., Dabbou, S., Brahmi, F., Ben Hassine, K., Hajaij Ellouze, M., \& Hammami, M. (2009). Effect of extraction systems and cultivar on the quality of virgin olive oils. International Journal of Food Science Technology, 44, 1713-1720. https://doi.org/10.1111/j.1365-2621.2009.01985.x

Issaoui, M., Flamini, G., Brahmi, F., Dabbou, S., Hassine, K. Ben, Taamali, A., ... Hammami, M. (2010). Effect of the growing area conditions on differentiation between Chemlali and Chétoui olive oils. Food Chemistry, 119(1), 220-225. https://doi.org/10.1016/j.foodchem.2009.06.012

Issaoui, M., Gharbi, I., Flamini, G., Cioni, P. L., Bendini, A., Gallina Toschi, T., \& Hammami, M. (2015). Aroma compounds and sensory characteristics as biomarkers of quality of differently processed Tunisian virgin olive oils. International Journal of Food Science and Technology, 50(8), 1764-1770. https://doi.org/10.1111/ijfs.12830

Jedermann, R., Ruiz-Garcia, L., \& Lang, W. (2009). Spatial temperature profiling by semi-passive RFID loggers for perishable food transportation. Computers and Electronics in Agriculture, 65(2), 145154. https://doi.org/10.1016/j.compag.2008.08.006

Karâa, M., \& Moranab, J. (2016). The determinants leading to the adoption of traceability: Adaptation to the Tunisian date sector. Supply Chain Forum, 17(1), 3-14. https://doi.org/10.1080/16258312.2016.1143205

Kärkkäinen, M. (2003). Increasing efficiency in the supply chain for short shelf life goods using RFID tagging. International Journal of Retail \& Distribution Management, 31(10), 529-536. https://doi.org/10.1108/09590550310497058

Lozano-Sánchez, J., Cerretani, L., Bendini, A., Gallina-Toschi, T., Segura-Carretero, A., \& FernándezGutiérrez, A. (2012). New filtration systems for extra-virgin olive oil: Effect on antioxidant compounds, oxidative stability, and physicochemical and sensory properties. Journal of Agricultural and Food Chemistry, 60(14), 3754-3762. https://doi.org/10.1021/jf205353b

Luvisi, A., Panattoni, A., Bandinelli, R., Rinaldelli, E., Pagano, M., \& Triolo, E. (2011). Implanting RFIDs into Prunus to facilitate electronic identification in support of sanitary certification. Biosystems Engineering, 109(2), 167-173. https://doi.org/10.1016/j.biosystemseng.2011.03.001

Luvisi, A., Triolo, E., Rinaldelli, E., Bandinelli, R., Pagano, M., \& Gini, B. (2010). Radiofrequency applications in grapevine: From vineyard to web. Computers and Electronics in Agriculture, 70(1), 256-259. https://doi.org/10.1016/j.compag.2009.08.007

Mansour, A. Ben, Gargouri, B., Flamini, G., \& Bouaziz, M. (2015). Effect of Agricultural Sites on Differentiation between Chemlali and Neb Jmel Olive Oils. J. Oleo Sci, 392(4), 381-392. https://doi.org/10.5650/jos.ess14204

Meixell, M. J. (2006). Quantifying the value of web services in supplier networks. Industrial Management and Data Systems, 106(3), 407-422. https://doi.org/10.1108/02635570610653524

Moore, B. (1999). Bar code or RFID: Which will win the high-speed sortation race? Automatic ID News, 15(7), 29-32. Retrieved from https://elibrary.ru/item.asp?id=3551638

Ollivier, M. (1995). RFID enhances materials handling. Sensor Review, 15(1), 36-39. https://doi.org/10.1108/EUM0000000004267

Othman, Z., Salim, N. A. A., Moosa, S., \& Mostapha, R. (2006). Establishing Food Traceability System Using Nuclear and Related, (Cac), 1-6.

Ouni, Y., Flamini, G., Issaoui, M., Nabil, B. Y., Cioni, P. L., Hammami, M., ... Zarrouk, M. (2011). Volatile compounds and compositional quality of virgin olive oil from Oueslati variety: Influence of geographical origin. Food Chemistry, 124(4), 1770-1776. https://doi.org/10.1016/j.foodchem.2010.08.023 
Papaefthimiou, D., Ventouris, A., \& Tabakis, I. (n.d.). OLEA Framework for non refined olive oil traceability and quality assurance, 91-103.

Pasqualone, A., Montemurro, C., Caponio, F., \& Blanco, A. (2004). Identification of Virgin Olive Oil from Different Cultivars by Analysis of DNA Microsatellites. Journal of Agricultural and Food Chemistry, 52(5), 1068-1071. https://doi.org/10.1021/jf0348424

Peets, S., Gasparin, C. P., Blackburn, D. W. K., \& Godwin, R. J. (2009). RFID tags for identifying and verifying agrochemicals in food traceability systems. Precision Agriculture, 10(5), 382-394. https://doi.org/10.1007/s11119-009-9106-4

Pristouri, G., Badeka, A., \& Kontominas, M. G. (2010). Effect of packaging material headspace, oxygen and light transmission, temperature and storage time on quality characteristics of extra virgin olive oil. Food Control, 21(4), 412-418. https://doi.org/10.1016/j.foodcont.2009.06.019

Qian, J. P., Yang, X. T., Wu, X. M., Zhao, L., Fan, B. L., \& Xing, B. (2012). A traceability system incorporating 2D barcode and RFID technology for wheat flour mills. Computers and Electronics in Agriculture, 89, 76-85. https://doi.org/10.1016/j.compag.2012.08.004

Regattieri, A., Gamberi, M., \& Manzini, R. (2007). Traceability of food products: General framework and experimental evidence. Journal of Food Engineering, 81(2), 347-356. https://doi.org/10.1016/j.jfoodeng.2006.10.032

Roberts, C. M. (2006). Radio frequency identification (RFID). Computers \& Security, 25(1), 18-26. https://doi.org/10.1016/j.cose.2005.12.003

Ruiz-Garcia, L., \& Lunadei, L. (2011). The role of RFID in agriculture: Applications, limitations and challenges. Computers and Electronics in Agriculture, 79(1), 42-50. https://doi.org/10.1016/j.compag.2011.08.010

Shutzberg, L. (2004). Radio Frequency Identification ( RFID ) In The Consumer Goods Supply Chain: Mandated Compliance or Remarkable Innovation?

Valli, E., Manzini, R., Accorsi, R., Bortolini, M., Gamberi, M., Bendini, A., ... Gallina Toschi, T. (2013). Quality at destination: Simulating shipment of three bottled edible oils from Italy to Taiwan. Rivista Italiana Delle Sostanze Grasse, 90(3), 163-169.

Vekiari, S. A., Papadopouloua, P., \& Koutsaftakisb, A. (2002). Comparison of different olive oil extraction systems and the effect of storage conditions on the quality of the virgin olive oil. Grasas y Aceites, 53, $324-329$.

Wang, L., Kowk, S. K., \& Ip, W. H. (2012). A radio frequency identification-based quality evaluation system design for the wine industry. International Journal of Computer Integrated Manufacturing, 25(1), 11-19. https://doi.org/10.1080/0951192X.2011.562542

Watts, A., Miller, P., \& Godwin, D. (2002). Applications of RFID (Radio Frequency Identification) in agriculture. Pesticide Outlook, 13(6), 254-258. https://doi.org/10.1039/b211207h

Yang, F., \& Wang, T. (2012). The application of radio frequency identification technology in vegetable quality traceability system. In 2012 International Conference on Systems and Informatics, ICSAI 2012 (pp. 1356-1359). https://doi.org/10.1109/ICSAI.2012.6223286 